\title{
Field investigation of Turtle doves' courtship: vocal calls versus arc-flight
}

\author{
Ismail Mansouri (D). Mohamed Dakki - Wafae Squalli • Driss Ousaaid iD . Said Elfalah • Lahcen Elghadraoui
}

\section{Mansouri (Corresponding author) - W Squalli • L \\ Elghadraoui}

Laboratory of Functional Ecology and Environment, Faculty of Sciences and Technology, Sidi Mohamed Ben Abdellah University, P.O. Box 2202 - Imouzzer Street, Fez, Morocco.

email: mankhori@gmail.com
M Dakki - S Elfalah

Center for the Study of Bird Migrations, Scientific Institute, Mohammed V University, Ibn Battota Street, P.O. Box 703, Agdal, 10106 Rabat, Morocco.

\section{Ousaaid}

Laboratory of Physiology, Pharmacology and Environmental Health, Faculty of Science Dhar El Mahraz, USMBA Fez, Morocco.

Received: August 06, 2019 - Accepted: September 10, 2019 - Published Online: September 30, 2019

\begin{abstract}
During the breeding season, many avian species produce complex expressions to attract their mates. In turtle doves Streptopelia turtur, male signals visually and acoustically during courtship. The only previous study on turtle doves' song was limited to quantifying acoustic expressions and their role in the detection of turtle doves. In the present study, we defined two types of languages in turtle dove's courtship display: "arc-shaped" flights and vocal "roux", with the aim to investigate, under natural conditions, their attractive role towards females. Similarly, the influence of intraspecific competitors and position of singing were analysed during two breeding seasons (2016-2017). Summarizing, results chow that male turtle doves combined acoustic and arc-flight displays to attract mates, with intense expressions between May and July. Throughout the day, vocal calls and flights are concentrated between 8:00-10:00 (morning) and 16:00-18:00 (evening). Moreover, the duration of the acoustic display is more important than flying expressions. On the other hand, turtle doves sing on trees (vertical support) more than ground, with a complex frequencies and amplitudes (sound calls) to spread out their calls toward females. However, the presence of competitors in the same field increase rate of singing and flying, in order to ensure mates attraction.
\end{abstract}

Keywords: Streptopelia turtur, courtship display, flight, song

\section{Introduction}

During the breeding season, many avian species produce a relatively complex behavioural expression to attract mates (Brumm 2002; Zollinger and Brumm 2015). Both sexes adopt a variety of communications, the most important are the acoustic and visual languages (Staler et al1988; Zann 1996; Livezey 2016). In songbirds, males direct their vocalisations toward females during courtship display (Sossinka and
Bohner 1980). However, in other species like Streptopelia risoria and Menura novaehollandiae, the males combine between songs and dances to better distribute their information (Fusani et al 1997; Dalziell et al 213). Despite, what is more effective (song or visual), female recipients are widely known by their sensitivity to male signals and respond with varying behaviours between acceptance and refuse (Neunuebel et al 2015; Pennycuick 2015; Finton et al 2017). In general, studies of audiovisual communications in birds are focused on controlled experiments in laboratories (Caryl 1981; Krieg and Getty 2016; Ullrich et al 2016), while captivity results can be very different from natural expressions (Solonen 2013).

In turtle dove (Streptopelia turtur) studies of breeding biology are very advanced (Hanane and Baâmal 2011; Kafi et al 2015). However, these researches concentrate on arrival dates (Herbert and Wilson 2013), spawning phenology, breeding success and population size. Works on turtle dove's sexual behaviour are very limited or even absent. In fact, two studies were conducted on two close species, Streptopelia risoria and Streptopelia decaoto, showed that, during courtship display, the male performs visual expressions (arch flights) accompanied with specific calls (Roux), in order to convince the female (Fusani et al 1997; Catchpole and Slater 2008). These aspects are crucial before any breeding success.

In this study, we pointed out two categories of behavioural expressions in the turtle dove's courtship display: "arc-shaped" flights and vocal "roux", in the object to analyse, under wild conditions, their attractive contribution towards females. We theorised that vocal expressions were very attractive more than arc flights. Similarly, we supposed that the sequence durations were variable according to the nature of the courtship display (acoustic or visual). The clarification of these fundamental features will offer essential keys to breeding success in turtle doves. 


\section{Materials and Methods}

Study sites

Ait Ayach valley (32०41'6" N and $4^{\circ} 44^{\prime} 42^{\prime \prime} \mathrm{O}$ ), is situated in the West of the Moulouya plain, Midelt Province, Morocco. The habitat is located in an altitude of $1500 \mathrm{~m}$, with an average annual rain of $182.06 \mathrm{~mm}$ and medium temperature of $15.72{ }^{\circ} \mathrm{C}$ (2015-2016). On the other hand, the prospected zone is cultivated mainly by apple orchards (1600 ha) which are suitable for Turtle dove breeding (more than 220 nests during 2015). Cereal surfaces cover 4500 ha and provide important food resources for this bird.

\section{Sample design}

The monitoring of courtship display in Turtle dove was carried out in different kinds of wild and agricultural habitats including apple orchards, riparian vegetation and cereal plots, during two breeding seasons (March to September 20162017). Basing on early field prospections during 2015, three viewpoints were fixed: Ayad hill (32 $36^{\circ} 15^{\circ} \mathrm{N}$ and $5^{\circ} 1{ }^{\prime} 8^{\prime \prime}$ $\mathrm{W})$, Boygra hill ( $32^{\circ} 36^{\prime} 388^{\prime N} \mathrm{~N}$ and $\left.5^{\circ} 0^{\prime} 51^{\prime \prime} \mathrm{W}\right)$ and Oalabbo in bowl topography $\left(32^{\circ} 37^{\prime} 4\right.$ "N and $5^{\circ} 0{ }^{\prime} 24$ "W). The chosen sites were topographically high for better visibility (better and easy pairs' counting), and camouflaged (apple trees and other riparian vegetation) to avoid any disturbance. Voice calls and arc flights were audio-recorded and videotaped during the whole day from 06:00 to 18:00, with microphone, Canon camera (LEGRIA HF R506, advanced zoom X57) and binoculars (in case of good visibility conditions). However, males singing inside trees and in camouflaged localities were audio recorded only. In case of the competition (presence of more than male singing and flying in the same locality), the recording was performed focusing on the first individual to display. Sequences' duration and the positions of their emission were noted for later analysis. In parallel with audiovisual behaviour, the observed pairs (in mating or just the two partners in meeting after each expression) were noted to analyse the relationship between the behavioural expressions and the pair's formation (witch of the expressions is more effective?). Moreover, distance between competitors was estimated basing on the distance between apple trees inside orchards (in Midelt apple orchards, tree lines are separated by $3.5 \mathrm{~m}$ as optimum distance) and Total Station (Topcon SANS PRISME (MODEL: NTS-102B, NTS-315B), Prismless range $500 \mathrm{~m}$ - Measurement time less than $1 \mathrm{sec}$ ).

\section{Sound analysis}

Recorded sound sequences (in HD format with camera and MP3 format with microphone devise $200 \mathrm{kHz}$ maximum range) during Turtle doves' acoustic courtship were converted to wave format (in audio.online-convert.com web site). During the analysis, sequences (wave formats) were calibrated to 25 second periods (basing on the sequences' maximum duration recorded in field (23s)), as in the case of house mice female calls (Finton et al 2017). Oscillograms and spectrograms were generated with SoundRuler software (SoundRuler 0.9.6.0; Macros Gridi-Papp, GNU GPL). Sequences were divided into syllables and sections basing on Oscillograms and using section length button. The section duration was measured (in millisecond) and compared between first segments (beginning of calls) and last segments (end of calls).

\section{Data analysis}

Statistical tests were executed in SPSS software (version 24.00, IBM 2009). Parametric data (checked with normality test), such as the comparison of vocal and flight sequences during the day and season and acoustic syllables, was analysed using the one-sample t-test. Non-parametric data (non-conform to the requirements for parametric tests) including sequence duration and the time interval between two successive sequences were compared by Wilcoxon and MannWhitney Sign Tests. In the case of sequences' duration, recorded displays were partitioned in tree periods; (i) beginning of breeding season (from arrival date to the end of April), (ii) optimum breeding phase (corresponding to courtship peaks in May and July), (iii) end of breeding season (August). Because of their non-conformity with parametric tests (checked with normality), sound and flight sequences (during three periods) were analysed with Kruskal-Wallis test. Results reported as significant assume a false discovery rate of 0.05. Graphs were created by GraphPad Prism Mac 6.0h software. The overall mate-attractiveness of acoustic and visual courtship was modelled by means of Generalised Linear Mixed Model (GLMM). In these analyses, arc flight was $\log (\mathrm{x}$ +1 ) transformed to ensure normality.

\section{Results}

\section{Seasonal and daily courtship display}

The expression of the two courtship languages differed qualitatively and quantitatively. Songs were more important than flying, during turtle dove's breeding season (Figure 1). In fact, songs were displayed from the second decade of April until the first week of August. In contrary, flights were limited to the period between the second week of May and the first week of July. In addition, during day, vocal expressions (72.88 \pm 13.14 sequences on average per day) were very intense in comparison with arc flight sequences $(12.13 \pm 2.50$ sequences in average per day) $(n=51, t=4.539, \mathrm{P}<0.001)$. However, turtle dove's courtship activities (flying and singing) were concentrated essentially between May and June, with a second recovery of songs at the beginning of July, as reflected by the peaks during these periods (Figure 1). In parallel, the 
formation of turtle dove's pairs follows the courtship peaks. In fact, the first pair's peak was recorded in coincidence with the parade peaks (songs and flight) between May and June. The second peak was distinct after the recovery peak of vocal expressions in July.

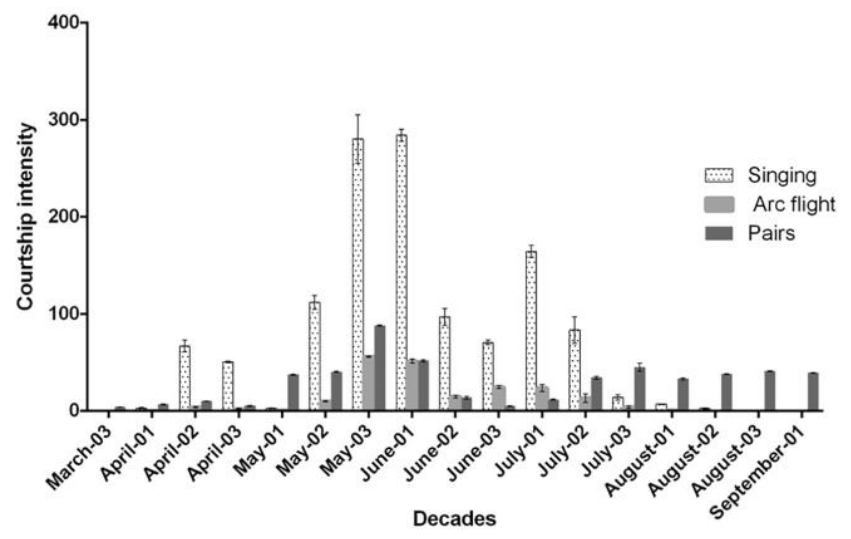

Figure 1 Courtship display (sound and flight) in Turtle doves during the breeding season (2016-2017).

Concerning the daily courtship, the intensity was variable (Figure 2). The expression of the two sequences (flights and songs) was more intense early between 08:00 and 10:00 during the morning and late between 16:00 and 18:00 during the evening (Table 1). However, acoustic activity is also more important than visual expressions. Indeed, t-test conducted on sequence duration of singing and flying demonstrated that the difference between these two expressions is widely significant $(n=18, t=4.824, \mathrm{P}<0.001)$.

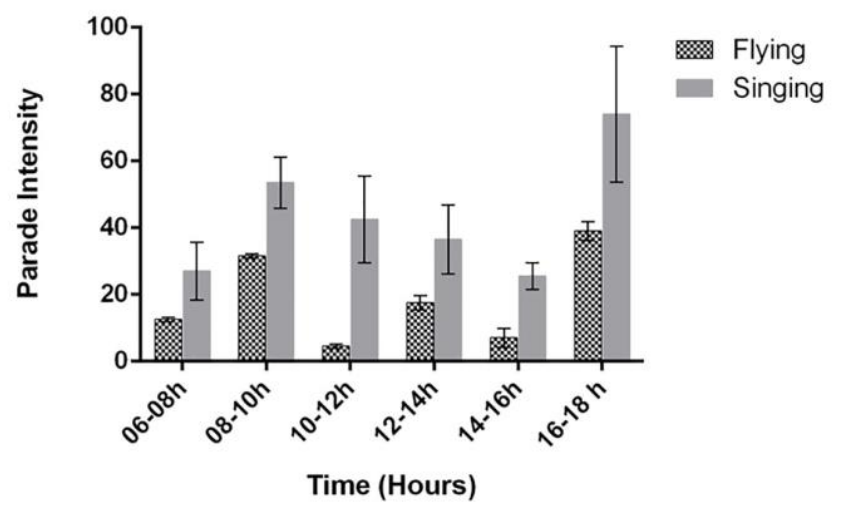

Figure 2 Daily (08:00 to 18:00) courtship intensity in Turtle doves, during breeding season (2016-2017).

\section{Sequences' duration}

Sequence length varied according to the nature of behavioural expression (Table 2). Seasonal acoustic activity, represented by the "roux" calls, take more time compared with visual expressions, reflected by the arc-shaped flights $(\mathrm{P}<$ 0.001). In contrary, the time intervals between two successive expressions were more important between flights in comparison with acoustic sequences $(\mathrm{P}<0.001)$. This indicates the high intensity of the songs in turtle doves, during the breeding season.

Concerning periods, the optimum breeding phase (May and July) was characterised by a sequences with long duration in vocalisation, while flight sequences were comparable in all periods (Kruskal-Wallis test for: (i) vocalisation: $H=37.648$, P $<0.001$; (ii) flight: $H=0.996, \mathrm{P}=0.60$ ).

Table 1 Multiple Range Tests showing the variation of daily courtship intensity in Turtle doves.

\begin{tabular}{lccc}
\hline Contrast & Sig. & Difference & +/- Limits \\
\hline 06:00-08:00_08:00-10:00 & - & -1.71429 & 5.30462 \\
06:00-08:00_10:00-12:00 & - & -1.92857 & 5.30462 \\
06:00-08:00_12:00-14:00 & - & -1 & 5.30462 \\
06:00-08:00_14:00-16:00 & - & 1 & 5.30462 \\
06:00-08:00_16:00-18:00 & $*$ & -5.57143 & 5.30462 \\
08:00-10:00_10:00-12:00 & - & -0.214286 & 5.30462 \\
08:00-10:00_12:00-14:00 & - & 0.714286 & 5.30462 \\
08:00-10:00_14:00-16:00 & - & 2.71429 & 5.30462 \\
08:00-10:00_16:00-18:00 & - & -3.85714 & 5.30462 \\
10:00-12:00_12:00-14:00 & - & 0.928571 & 5.30462 \\
10:00-12:00_14:00-16:00 & - & 2.92857 & 5.30462 \\
10:00-12:00_16:00-18:00 & - & -3.64286 & 5.30462 \\
12:00-14:00_14:00-16:00 & - & 2 & 5.30462 \\
12:00-14:00_16:00-18:00 & - & -4.57143 & 5.30462 \\
14:00-16:00_16:00-18:00 & $*$ & -6.57143 & 5.30462 \\
\hline
\end{tabular}

$*$ denotes a statistically significant difference.

\section{Structure of acoustic sequences}

Oscillogram of turtle dove's voice call (Figure 3) chowed a complexity in vocalisation sequences. In fact, every sequence is divided on $6.35 \pm 0.67$ segment ( $n=12$ audio recordings). Similarly, each segment is partitioned on three syllables. This small sections were different between the beginning $(7.81 \pm 0.27 \mathrm{~ms})$ and the end $(9.58 \pm 0.31 \mathrm{~ms})$ of segments $(n=12, t=31.657, \mathrm{P}<0.001)$.

The field survey of acoustic courtship showed two main situations for expression; the position on the trees and ground singing. However, statistical calculation confirmed that the turtle dove prefers trees more than ground to express their acoustic display (Table 3). In fact, during six months of monitoring, the acoustic activities, expressed on trees, exceed largely the ground songs $(\mathrm{P}<0.05)$. Furthermore, no difference was recorded concerning the sequence durations between two positions $(\mathrm{P}>0.05)$.

\section{Discussion}

Through this field-based study, we investigated the use of visual and acoustic signals in Turtle dove's courtship display. North African Turtle dove, especially the males, uses 
both acoustic and visual expressions (Figure 1,2) to attract females. Our results agree with previous experimental studies on other bird species, including passerines (Larsen and Dabelsteen 1990; Gate et al 2005; Patricelli 2007; StangerHall et al 2018) and support that these birds use both visual and acoustic languages during sexual behaviour. Moreover, some avian species combine between this two signal modules to improve and/or maximize the information exchange, as has been shown in zebra finch and other birds (Wang et al 2008; Ullrich et al 2016; Kaplan 2017). However, the present work shows paradoxical results. In the field, acoustic courtship dominated the theatre (Figure 1), while the statistical analyses, using Generalised Linear Mixed Model (GLMM), indicated a relative link between visual behaviour (flight) and formation of breeding pairs (Figure 4).

Table 2 Duration (time in seconds) differences between flying and singing in turtle dove's courtship, during breeding season.

\begin{tabular}{|c|c|c|c|c|c|}
\hline \multicolumn{2}{|c|}{ Courtship categories } & Singing (s) & Flying (s) & $\mathrm{Z}$ & $P$-value \\
\hline \multirow{4}{*}{ 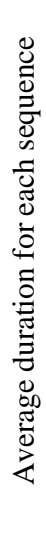 } & & $8.10 \pm 3.69$ & $5.65 \pm 2.70$ & -6.548 & $<0.0001$ \\
\hline & $\begin{array}{l}\text { Beginning of season } \\
\qquad(N=20)\end{array}$ & $5.00 \pm 0.35$ & $5.80 \pm 0.68$ & -0.774 & 0.438 \\
\hline & $\begin{array}{l}\text { Optimum breeding } \\
\text { periods }(N=20)\end{array}$ & $9.10 \pm 0.67$ & $7.00 \pm 0.80$ & -2.183 & 0.029 \\
\hline & $\begin{array}{l}\text { End of breeding } \\
\text { periods }(N=20)\end{array}$ & $2.55 \pm 0.43$ & $5.75 \pm 0.59$ & -3.995 & $<0.0001$ \\
\hline & $\begin{array}{l}\text { rval between two } \\
\text { sequences }\end{array}$ & $1930.38 \pm 1613.52$ & $24955.83 \pm 4361.5$ & -4.961 & $<0.0001$ \\
\hline
\end{tabular}
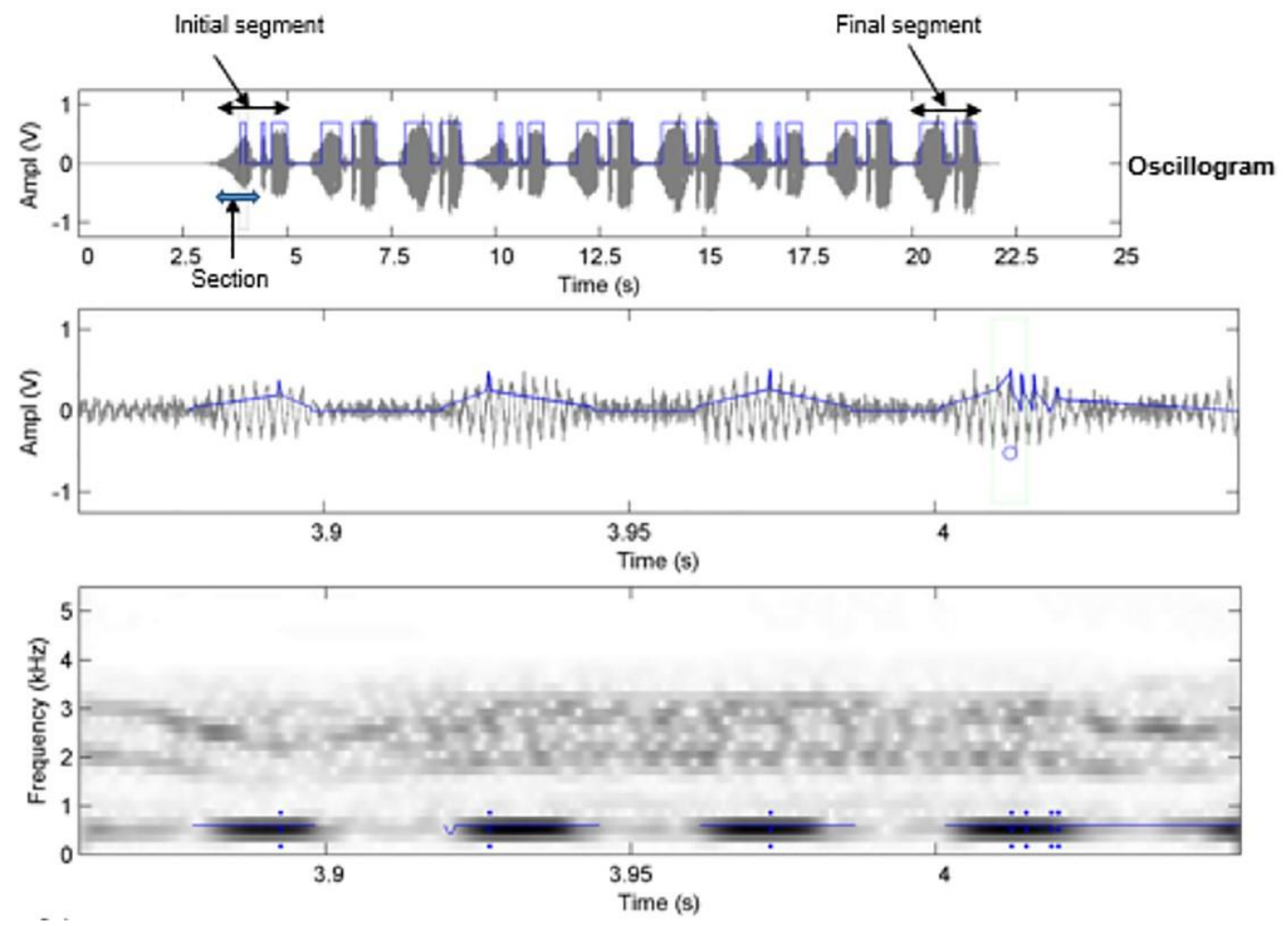

Figure 3 Oscillogram (top) and spectrograms (bottom) of sample broadband vocalizations illustrating the complexity (multiple syllables (sections)) of courtship call's structure in Turtle dove. 
Table 3 Differences between singing on tree and singing on the ground ( $\mathrm{N}=10$ days spread-out equally between April and July) in apple orchards and riparian vegetation, Morocco, 2016.

\begin{tabular}{ccccc}
\hline Singing position & On the tree & On ground & Test & P-value \\
Total sequences & 415 & 89 & - & - \\
Average sequences per day & $75.45 \pm 9.56$ & $16.18 \pm 3.33$ & $F=10.36$ & 0.005 \\
Average duration for one sequence (s) & $7.77 \pm 0.48$ & $8.35 \pm 0.74$ & $U=-0.004$ & 0.99 \\
\hline
\end{tabular}
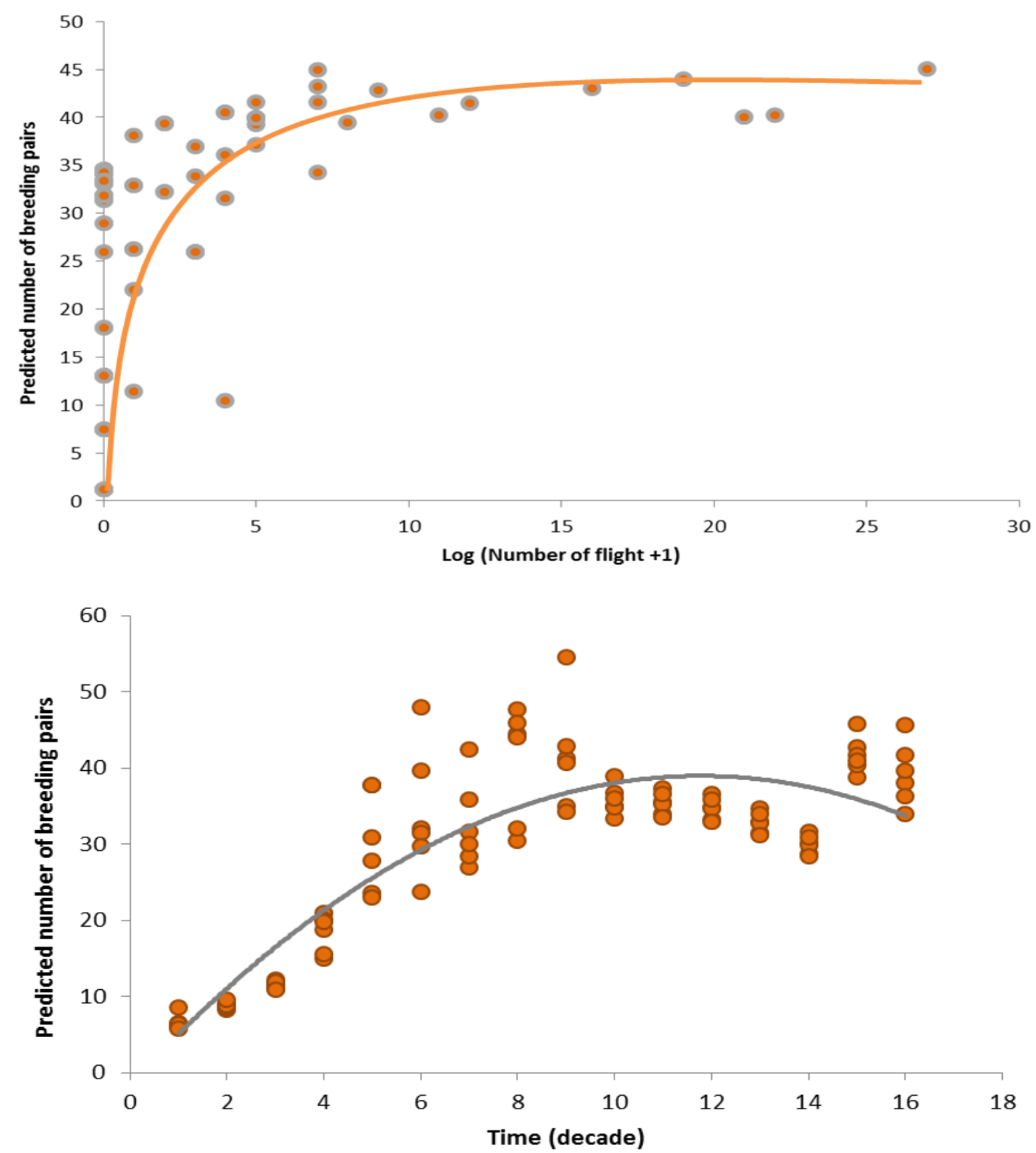

Figure 4 GLMM model predicting the Mate-attractiveness (pair formation) of visual expressions (Flight above) and time (decades below) during Turtle dove's courtship. 
This finding can be explained by two elements. First, our approach was observational and, therefore, the acoustic dominance was very easy to be distinguished in field, since sound easy-dissemination (Hick et al 2016; Potvin et al 2018), even if its effectiveness would be useless as in Cervus elaphus (Reby and McComb 2003), in which a negative correlation between reproductive success and acoustic courtship was reported. Second, the visual signal (flights) was revealed recently to be a good physical indicator of the presence and body performance of the partner (Zhang et al 2018), which could make it more attractive with its quality note by the intensity. This is in contradictory with results obtained by (Kroodsma and Miller 1982; Cramp 1985; Bhatt et al 2000) who have reported that the acoustic expressions are very important in bird's courtship display, in particular, loud songs can spread out over a long distance, stimulate the fitness and mark the territory (Gil and Gahr 2002; Kaplan et al 2009; Ohms et al 2012). However, the main question in this topic is which expression is more effective in mate attraction. In reality, with contradiction found between field and laboratory analyses, our results suggested a synergetic effectiveness combining sound and flight, as found in warbler and zebra finches that combine between plumage or flights, as a visual behaviour and acoustic songs in fitness components (Avey et al 2005). This combination could offer an audio signature, while the visual behaviour could provide the image of the partner and its performances. On other side, recipient females are basing on these two channels and their amplitude to make a virtual conception (image) of potential partners, in particular, their physical quality and motivation state (Collins et al 1994; Boukhriss and Selmi 2009; Perez et al 2015; Zollinger and Brumm 2015). Similar results were recorded in domesticated Australian zebra finch and other lyrebirds (Ullrich et al 2016; Dalziell et al 2013; Mulder and Hall 2013), which integrate courtship song and dance in order to attract effectively the mate. The mesmerising effect of sound and movement is not limited to birds, it's a common strategy adopted by other animals, including spiders and compared with humans dancing to music (Ejima and Griffith 2008; Mulder and Hall 2013).

Seasonal parade was variable, courtship intensity was very high, essentially between May, June, and July. These periods (May, June and July) correspond exactly to the turtle dove's optimum nesting phases, as reported in North African areas (Calladine et al 1999; Nemeth et al 2012; Hanane 2016, 2017; Rieger and Marler 2018). Likewise, during the day, sequence intensities varied from one period to another. Expression peaks were recorded between 08:00 and 10:00 during the morning and between 16:00 and 18:00 during the evening (Figure 2). The choice of these phases to display courtship may be due to the fresh weather conditions during the morning and evening. As this is already cited in the turtle dove dietary behaviour and singing rate (Browne and Aebischer 2004; Nemeth et al 2012; Linhart and Fuchs 2015). This columbidae sings and researches its food out of the day hot periods (midday) to avoid or limit the water loss due to perspiration. In fact, the parade activity requires a very important physical effort, particularly in the presence of intraspecific competitors that require more effort, in order to ensure field dominance (Dubois 2002; Kaplan et al 2009; Hick et al 2015). Consequently, we examined courtship in the presence of competitors (Figure 5). As a results, turtle doves, in the presence of other intraspecific competitors (male turtle doves displaying in the same habitat and period), increases rate of songs (with competitors: $6.34 \pm 0.20$ song sequences, compared with $3.5 \pm 0.21$ repetitions in the absence of competitors, one-sample t-test, $N=32, t=-9.482, \mathrm{P}<0.001$ ) and flights (with competitors: $2.09 \pm 0.25$ flight repetitions against $0.81 \pm 0.13$ repetitions in the absence of competitors, $t$ test, $N=32, t=-4.381, \mathrm{P}<0.001$ ) before engaging mate or leaving the territory (in case of fail engaging).

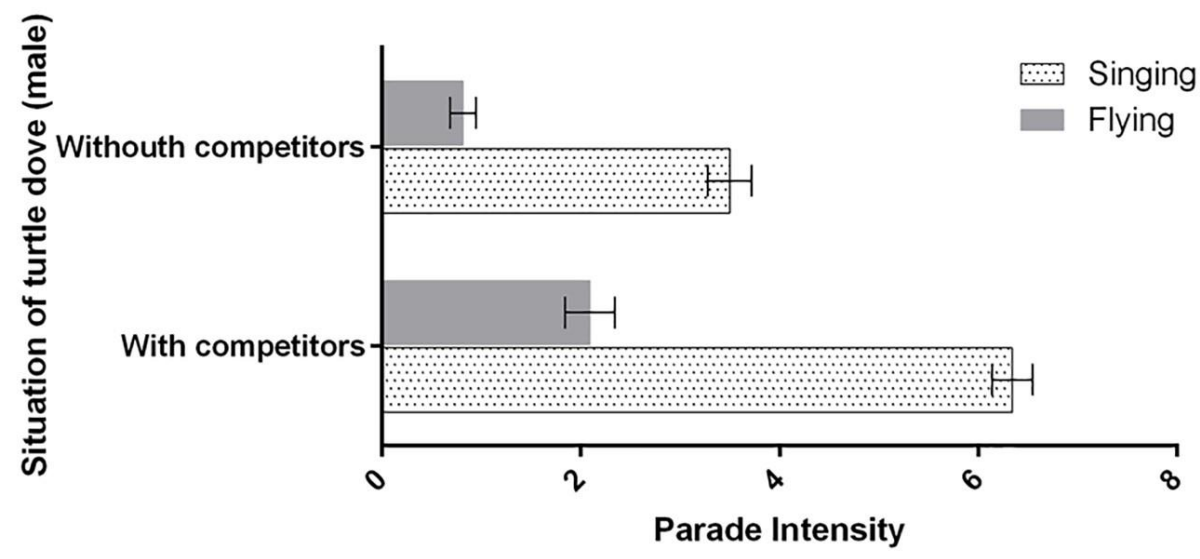

Figure 5 Variation of courtship display in Turtle dove depending on the presence or absence of competitors in the same habitat. 
The analysis of the acoustic expressions showed a complexity in turtle dove vocalisation (Figure 3 ). The calls were formed with small segments (syllables) that were variable between individuals. Further, segments were divided into three syllables with variable duration and frequency between the first and the last one. This variation and complexity in sound calls (three syllables) could be governed by the difference in physical fitness of male turtle doves. In fact, many animal species, such as red deer stags where the roars were complex (common and harsh roars) and influenced by the male fitness and body size (Hick et al 2016). On other hand, sexual competition with other intraspecific birds could interfere in this complexity. Therefore, in order to propagate convincing calls (for females), males produce specific call segments with different amplitude and frequency that indicating their good physical quality and sexual motivation (Fant 1960; Reby and Mccomb 2003; Hanane and Maghnouj 2005; Hick, Doucet and Mennill 2016).

Turtle dove sings in two positions: on trees and on the ground. However, calls emitted on the tree were more important than those produced on the ground, in terms of quantity. In the opposite, the average duration was comparable between these two positions. Dominance of calls on trees as vertical support will facilitate the signal propagation (Fitch and Reby 2001). Particularly, these Columbidae use multidimensional calls in order to spread out the signals and to dominate competitors (Goodwin 1970; Fusani et al 1997; Mathevon et al 1997). Indeed, during the courtship displays, distances between competitors (males emitting the sequences at the same time) were very short (in order of $65.06 \pm 8.19 \mathrm{~m}$ during the whole season), in particular between May and July $(31.18 \pm 3.56 \mathrm{~m}$, corresponding to the optimum breeding phase). As a result, songs on trees can spread out more and can help competitors to attract the female's attention and supress the competitor's sound.

\section{Conclusions}

In summary, this paper provides a qualitative (seasonal and daily) and quantitative (time and sequences) analysis of courtship display in turtle doves during the breeding season, under wild condition. We revealed a synergetic effectiveness of acoustic and visual signals with a field dominance of sound sequences compared to visual arc-shaped flights in the attraction of mates. In addition, expressions increased in the presence of competitors on the same habitats. Similarly, turtle doves sing on the tree position with the use of multidimensional calls (diverse syllables with variable amplitudes and frequencies), to ensure a long propagation of sound (calls) and competitor's dominance. Despite its limitation to the quantification of acoustic and visual courtship, this initial research has decrypted a basic information (signalling language) on the sexual behaviour of turtle doves, under wild conditions and opened the window for future researches to reduce the lack of data on the breeding behaviour of this threatened bird.

\section{Acknowledgements}

We are grateful to our colleagues who helped in collecting data and hunting associations in Midelt province.

\section{Conflict of Interest Statement}

We confirm that we have no conflicts of interest.

\section{References}

Avey MT, Phillmore LS and MacDougall-Shackleton SA (2005) Immediate early gene expression following exposure to acoustic and visual components of courtship in zebra finches. Behavioural Brain Research 165:247-53.

Bhatt D, Kumar A, Singh Y and Payne RB (2000) Territorial songs and calls in Oriental magpie robin Copsychus saularis. Current Science 78:722-728.

Boukhriss J and Selmi S (2009) Nidification et succès reproducteur de la Tourterelle maillée Streptopelia senegalensis dans une oasis du Sud tunisien. Alauda 77:187-192.

Browne SJ and Aebischer NJ (2004) Temporal changes in the breeding ecology of European Turtle Doves Streptopelia turtur in Britain, and implications for conservation. Ibis 146:125-137.

Brumm H (2002) Sound radiation patterns in nightingale (Luscinia megarhynchos) songs. Journal of Ornithology 143:468-471.

Calladine J, Buner F and Aebischer NJ (1999) Temporal variations in the singing activity and the detection of Turtle Doves Streptopelia turtur: implications for surveys. Bird Study 46:74 -80.

Caryl P (1981) The relationship between the motivation of directed and undirected song in the zebra finch. Zeitsch Tierpsychol 57:3750 .

Catchpole CK and Slater PLB (2008) Bird Song: Biological Themes and Variations. Cambridge University Press, Cambridge, UK.

Collins SA, Hubbard C and Houtman AM (1994) Female mate choice in the zebra finch - the effect of male beak colour and male song. Behavioral Ecology and Sociobiology 35:21-5.

Cramp S (1985) The Birds of the Western Palearctic Vol IV. Oxford University Press, Oxford, UK.

Dalziell A, Peters R, Cockburn A, Dorland AD, Maisey AC and Magrath RD (2013) Dance choreography is coordinated with song repertoire in a complex avian display. Current Biology 23:11321135 .

Dubois MC (2002). Contribution à l'étude de la tourterelle des bois (Streptopelia Turtur): Biologie, Zoologie, Chasse. Ecole Nationale Vétérinaire. Toulouse, France.

Ejima A and Griffith LC (2008) Courtship Initiation Is Stimulated by Acoustic Signals in Drosophila melanogaster. PLoS ONE 3:e3246.

Fant G (1960) Acoustic Theory of Speech Production. The Hague, Mouton. 
Finton CJ, Keesom SM, Hood KE and Hurley LM (2017) What's in a squeak? Female vocal signals predict the sexual behaviour of male house mice during courtship. Animal Behaviour 126:163-175.

Fitch WT and Reby D (2001) The descended larynx is not uniquely human. Proceedings of the Royal Society London Series B 268:16691675.

Fusani L, Hutchison RE and Hutchison JB (1997) Vocal-postural coordination of a sexual dimorphic display in a monomorphic species: the Barbary dove. Behaviour 134:321-335.

Gate CT, Slabbekoorn H and Ballintijn MR (2002) Birdsong and Male-Male Competition: Causes and Consequences of Vocal Variability in the Collared Dove (Streptopelia decaocto). Advances in the Study of Behavior 31:31-75.

Gil D and Gahr M (2002) The honesty of bird song: multiple constraints for multiple traits. Trends in Ecology and Evolution 17:133-141.

Goodwin D (1970) Pigeons and Doves of the World. British Museum, London, UK.

Hanane S (2016) Effects of orchard type and breeding period on Turtle Dove nest density in irrigated Agroecosystems. Bird Study 63:141-145.

Hanane S (2017) The European Turtle-dove Streptopelia turtur in Northwest Africa: a review of current knowledge and priorities for future research. Ardeola 64:273-287.

Hanane S and Baâmal L (2011) Are Moroccan fruit orchards suitable breeding habitats for Turtle doves Streptopelia turtur. Bird Study 58:57-67.

Hanane S and Maghnouj M (2005) Biologie de reproduction de la Tourterelle des bois Streptopelia turtur dans le périmètre irrigué du Haouz (Marrakech-Maroc). Alauda 73:183-194.

Herbert W and Wilson JR (2013) A Deeper Statistical Examination of Arrival Dates of Migratory Breeding Birds in Relation to Global Climate Change. Biology 2:742-754.

Hick KG, Doucet SM and Mennill DJ (2015) Interspecific vocal discrimination in Neotropical wrens: responses to congeneric signals in sympatry and allopatry. Animal Behaviour 109:113-121.

Hick KG, Doucet SM and Mennill DJ (2016) Tropical wrens rely more on acoustic signals than visual signals for inter- and intraspecific discrimination. Animal Behaviour 118:153-163.

Kafi F, Hanane S, Bensouilah T, Zeraoula A, Brahmia H and Houhamdi M (2015) Les facteurs déterminant le succès de la reproduction des tourterelles des bois (Streptopelia turtur) dans un milieu agricole Nord-Africain. Revue d'écologie (la Terre et la Vie) 70:271-279.

Kaplan G, Johnson G, Koboroff A and Rogers LJ (2009) Alarm Calls of the Australian Magpie (Gymnorhina tibicen): Predators Elicit Complex Vocal Responses and Mobbing Behaviour. Open Ornithology Journal 2:7-16.

Kaplan G (2017) Audition and Hemispheric Specialization in Songbirds and New Evidence from Australian Magpies. Symmetry 9:99.

Krieg CA and Getty T (2016) Not just for males: females use song against male and female rivals in a temperate zone songbird. Animal Behaviour 113:39-47.

Kroodsma DE and Miller EH (1982) Acoustic Communication in Birds, Song learning and its consequence. Academic Press, New York.
Larsen ON and Dabelsteen T (1990) Directionality of blackbird vocalisation: Implications for vocal communication and its further study. Ornis Scandinavica 21:37-45.

Linhart P and Fuchs R (2015) Song pitch indicates body size and correlates with males' response to playback in a songbird. Animal Behaviour 103:91-98.

Livezey K (2016) An Approach to identifying bird songs: A Key to more than 300 Songs in the Pipeline Road Area, Soberanía National Park, Panama. Open Ornithology Journal 9:70-112.

Mathevon N, Aubin T and Brémond JC (1997) Propagation of bird acoustic signals: comparative study of starling and blackbird distress calls. Comptes Rendus de l'Académie des Sciences - Series IIISciences de la Vie 320:869-876.

Mulder RA and Hall ML (2013) Animal Behaviour: A Song and Dance about Lyrebirds. Current Biology 23:518-519.

Nelson BS, Beckers GJI and Suthers RA (2005) Vocal tract filtering and sound radiation in a songbird. Journal of Experimental Biology 208:297-308.

Nemeth E, Kempenaers B, Matessi G and Brumm H (2012) Rock sparrow song reflects male age and reproductive success. PloS One 7:e43259.

Neunuebel JP, Tayor AI, Arthur BJ and Egnor SE (2015) Female mice ultra-sonically interact with males during courtship displays. Elife 4:e6203.

Ohms VR, Escudero P, Lammers K and Ten Cate C (2012) Zebra finches and Dutch adults exhibit the same cue weighting bias in vowel perception. Animal Cognition 15:155-161.

Patricelli GL, Dantzker MS and Bradbury JW (2007) Differences in acoustic directionality among vocalizations of the male red-winged blackbird (Agelaius pheoniceus) are related to function in communication. Behavioral Ecology and Sociobiology 61:10991110 .

Pennycuick CJ (2015) The Flight of Birds and Other Animals. Aerospace 2:505-523.

Perez EC, Fernandez MSA, Griffith SC and Soula HA (2015) Impact of visual contact on vocal interaction dynamics of pair-bonded birds. Animal Behaviour 107:125-137.

Potvin DA, Ratnayake CP, Radford AN, and Magrath RD (2018) Birds Learn Socially to Recognize Heterospecific Alarm Calls by Acoustic Association. Current Biology 28:2632-2637.

Reby D and Mccomb K (2003) Anatomical constraints generate honesty: acoustic cues to age and weight in the roars of red deer stags. Animal Behaviour 65:519-530.

Rieger NS and Marler CA (2018) The function of ultrasonic vocalizations during territorial defence by pair-bonded male and female California mice. Animal Behaviour 135:97-108.

Solonen T (2013) Factors Affecting Timing of Breeding in the Tawny Owl Strix aluco. Open Ornithology Journal 6:40-51.

Sossinka R and Bohner J (1980) Song Typein zebra finch Poephila guttata castamotis. Zeitsch Tierpsychol 53:123-132.

Staler PJB, Eales LA and Clayton NS (1988) Song learning in zebra finches progress and prospects. In Advances in the study of Behavior. Academic Press, London, UK.

Stanger-Hall KF, Sander Lower SE, Lindberg L, Hopkins A, Pallansch J and Hall DW (2018) The evolution of sexual signal modes and associated sensor morphology in fireflies (Lampyridae, Coleoptera). Proceeding of the Royal Society B 285:2017-2384. 
Ullrich R, Norton P and Scharff C (2016) Waltzing Taeniopygia: integration of courtship song and dance in the domesticated Australian zebra finch. Animal Behaviour 112:285-300.

Wang CZH, Herbst JA, Keller GB and Hahnloser RHR (2008) Rapid interhemispheric switching during vocal production in a songbird. PLoS Biology 6:1-9.

Zann RA (1996) The Zebra Finch: A Synthesis of Field and Laboratory Studies. Oxford University Press, Oxford, UK.
Zhang S, Yip H-Y, Lee M-Y, Liu L, Piorkowski D, Liao C-P \& Tso I-M (2018) Vision-mediated courtship in a nocturnal arthropod. Animal Behaviour 142:185-190.

Zollinger SA and Brumm, H. (2015) Why birds sing loud and why they sometimes don't. Animal Behaviour 105:289-295. 